vol.4 No.1 - 2017

\title{
CHEMOTHERAPY SAFETY PROTOCOL FOR \\ ONCOLOGY NURSES: IT'S EFFECT ON THEIR PROTECTIVE MEASURES PRACTICES
}

\author{
${ }^{1}$ Samah Abd-Elhai Abd-Elghani Shetaia, ${ }^{2}$ Dr. Wafaa Ismail Shereif, \\ ${ }^{3}$ Dr.Eman Sobhy Omran \\ 1B.SC. Nursing - Benha University (2010) \\ 2Professor of Medical-Surgical Nursing - Faculty of Nursing Mansoura University \\ 3Lecturer of Medical-Surgical Nursing - Faculty of Nursing Benha University \\ samahshetaya@gmail.com
}

\begin{abstract}
Chemotherapy is a pharmacological compound that inhibits the proliferation of cells within the body. Several studies have shown that exposure to chemotherapy can cause toxic effects on reproduction system and carcinogenic effects on health-care worker especially nurse. So nurses should know how to protect themselves, their patients, and their work environment against toxic effect of chemotherapy. Aim of this study was carried out to examine the effect of chemotherapy safety protocol for oncology nurses on their protective measure practices. Research questions are: What is the effect of chemotherapy safety protocol for oncology nurses on knowledge about protective measures practice for chemotherapy handling and administration? What is the effect of chemotherapy safety protocol for oncology nurses on their protective measures practice? Design: A quasiexperimental research design was utilized. Setting: This study was conducted in the medical department at Benha University Hospital and National Cancer Institute at Cairo University. Sample of this study composed of 45 nurse who are dealing with chemotherapy drugs (10) nurses from Benha University Hospital and (35) nurses from National Cancer Institute at Cairo University. Two data collection tools were used: First tool: Assessment questionnaire sheet. Second tool: Observational checklist for nursing practice. Results of the study showed that statistical significant improvement in to nurse's knowledge and practice after implementing chemotherapy safety protocol. Conclusion: there is a positive effect of chemotherapy safety protocol on nurse's knowledge and practice about chemotherapy. Recommendation: chemotherapy safety protocol should be revised, updated, and available in oncology unit in both Arabic and English language.

Key words: Chemotherapy, Oncology nurses, Protective measures practices, Safety protocol
\end{abstract}

\section{Introduction:}

Cancer is a group of disease characterized by abnormal, unrelated cell proliferation, cancerous tumor invade healthy tissues and compete with normal cells for oxygen, nutrients, and space. More than 11 million cancer cases diagnosed each year worldwide and expected to rise to 16 million by the year 2020 (1). About 165,000 children under 15 years of age were diagnosed with cancer. The risk of cancer increases significantly with age and many cancers occur more commonly in developed countries. Rates are increasing as more people live to an old age and as lifestyle changes occur in the developing world. The number of staff potentially exposed to hazardous effect of the chemotherapy drug was more than 5.5 million (2). There are three basic methods are used to treat cancer: surgery, radiation therapy, and chemotherapy (1). 
Chemotherapy (cytotoxic drugs) refers to a wide range of drugs or compounds used to treat cancer. These drugs usually work by killing dividing cells. These compounds such as the alkylating agents and the ant metabolites designed to destroy cells (with a high growth fraction). Cytotoxic agents have a potential for producing teratogenesis, mutagenesis, and carcinogenesis on health care worker (3).

Several studies have shown that exposure to cytotoxic drugs can cause toxic effects on reproduction system and carcinogenic effects on health-care worker especially nurse (4). Occupational exposure may occur where control measures fail or are not in place. Exposure may be through skin contact, skin absorption, inhalation of aerosols and drug particles; ingestion and needle stick injuries resulting from the following activities: drug preparation, drug administration, handling patient waste, transport and waste disposal, or spills (5).

Health effects attributed to cytotoxic drugs exposure amongst people preparing and administering cytotoxic drugs include: abnormal formation of cells and mutagenic activity, alterations to normal blood cell count, fetal loss and malformations in the offspring of pregnant women, abdominal pain, hair loss, nasal sores and vomiting, liver damage, and contact dermatitis, local toxic or allergic reaction, which may result from direct contact with skin or mucous membranes (6).

So that oncology nurses who work with cytotoxic medications or other substances, precautions are recommended specifically to avoid carcinogenicity and mutagenicity. The specific precautions will vary considerably based on the route of possible exposure but may include: wear gloves, disposable gowns with long sleeve, safety glasses, and respiratory protection (7).

In the same point the broad measures described for oncology nurses are reducing the quantities of drugs used; the number of employees potentially exposed; and their duration of exposure, ensuring safe handling, storage and transport of cytotoxic drugs and waste material; using good hygiene practices and providing suitable welfare facilities, e.g. preventing eating, drinking and smoking in areas where drugs are handled and providing washing facilities; training staff who handle cytotoxic drugs or deal with contaminated waste $(\mathbf{8})$.

The following protective measures must be used when handling patients' vomitus, blood, excreta and fluid drained from body cavities which are contaminated with cytotoxic agents. (1)wear personal protective equipment.(2) Patient waste such as urine, faeces, vomitus and the contents of colostomy and urostomy bags may be disposed of in the normal sewerage system.(3)Double flushing is not required the use of disposable nappies is recommended. Disposable nappies, colostomy and urostomy bags must be disposed of in purple cytotoxic waste containers. (4)Wash hands with soap and water immediately after handling cytotoxic excrement (9). Therefore, this study was conducted to examine nurses' protective measures during chemotherapy preparation and administration at medical department at Benha University Hospital and National Cancer Institute (NCI) at Cairo University.

\section{Aim of the study}

The aim of this study is to examine the effect of chemotherapy safety protocol for oncology nurses on their protective measure practices.

\section{Research questions}

To achieve the aim of this study the following research questions were formulated:

1- What is the effect of chemotherapy safety protocol for oncology nurses on knowledge about protective measures 


practice for chemotherapy
handling and administration?
2- What is the effect of
chemotherapy safety protocol for
oncology nurses on their
protective measures practice?

Subjects and Methods

\section{Research Design:}

Quasi- experimental research design was conducted to achieve the aim of this study.

\section{Setting:}

This study was conducted at medical department at Benha University Hospital and National Cancer Institute (NCI) at Cairo University.

\section{Subjects:}

Sample of this study compromised of 45 nurse of both sex to achieve the aim of study (10) nurses from Benha University Hospital and (35) nurse from National Cancer Institute at Cairo University and are fulfilling the following criteria:

1. Staff nurses who are dealing with chemotherapy drugs through preparation and administration for cancer patients.

2. Staff nurses who are agreed to participate in this study.

Tools of the study:

Two tools were used in this study by the researcher for collection of necessary data and achieving the aim of the study as follows:

Tool I: Assessment questionnaire sheet (Appendix I)

Tool II: Observational checklist for nursing practice (Appendix II)

Tool I: Assessment questionnaire sheet (Appendix I)

It was developed by researcher to collect the required baseline data and evaluate nurses' knowledge about chemotherapy, which divided into three parts.
First part: Socio-demographic data sheet:

It was used for collection of personal data such as name, gender, age, marital status, educational level, number of years as registered nurse and oncology nurse, nature of their contact with chemotherapy and work setting.

Second part: Nurse knowledge questionnaire about health problems due to contact with chemotherapy:

It was used for collection of health problems related to contact with chemotherapy as headache, dermatitis, cough, abortion, fatigue, air loss, and recurrent infection.

Third part: Nurse knowledge questionnaire about chemotherapy: (pre and post-test)

This tool was developed by the researcher aimed to evaluate nurse's knowledge about chemotherapy after reviewing recent literature. Originally, this tool consisted of five subscale parts:

Part (1) Knowledge about chemotherapy: It consists of 5 items to investigate knowledge about chemotherapy definition, effectiveness on cells, if chemotherapy considers general treatment for recovery from cancer or not, which cells chemotherapy effect more rapidly, and its preparation

Part (2) Routes of chemotherapy administration and its duration: It consists of 3 items to assess nurse awareness about chemotherapy forms, duration of its effect on patient after giving dose, and nurses precaution during handling with patient excretion.

Part (3) Side effect of chemotherapy on patient: It consists of 4 items to assess nurse awareness about chemotherapy side effect on patient after administration (respiratory system, circulatory system, gastrointestinal system, urinary system, nervous system, reproductive system, musculoskeletal system, and integumentary system), if patient can eat 
directly after vomiting, which food was preferred after vomiting occurrence, and how to decrease incidence of alopecia.

Part (4) Patient preparation before and during administration of dose: It consists of 5 items to know what nurses do for patient before receiving chemotherapy dose, nurse should do CBC for patient before giving dose, if there is decrease urine output during administration of dose, if nurse give patient fluid in case of decrease urine output, if there is fever during administration of dose, and if nurse should stop administration of chemotherapy in case of fever.

Part (5) Precaution during and after chemotherapy administration: It consists of 7 items that covering nurse's knowledge about actions that should take in cases of chemotherapy spillages on nurse skin, extravasation, spillages on eye, if there is polices on the center for waste of empty chemotherapy bottle, what is the route for waste, if chemotherapy bottle account for normal bottle or dangerous waste, and what is the route to waste residual amount of chemotherapy.

\section{Scoring system:}

Each item in the sheet was given a score. One mark was given to correct answer, and a zero for in correct answer or unknown. Then the scores were summed up, the total score in this part was 46 marks (100\%). Then score \% was transferred into categories as follow:

\begin{tabular}{|l|l|}
\hline Percentage & $\begin{array}{l}\text { Knowledge } \\
\text { categories }\end{array}$ \\
\hline$\geq 80 \%$ & Adequate \\
\hline$<80 \%$ & Inadequate \\
\hline
\end{tabular}

Tool II: Observational checklist for nursing practice (pre and post- test) (Appendix II)

This tool was developed by researcher after extensive literature review. It aimed to evaluate nurses' practice during handling with chemotherapy; it consisted of 4 sub scale checklist as the following:
- Observational checklist for nurses during chemotherapy administration $=11$

- Observational checklist for nurses after chemotherapy administration $=12$

Observational checklist for nurses during extravasations $=12$ -

- Observational checklist for nurses during spillages $=21$

\section{Scoring system:}

Each item in the checklists was given a score. One mark was given if nurse was did this step, and zero mark was given if nurse didn't done this step. Then the scores were summed up, the total score in this part was 56 marks (100\%). Then score \% was transferred into categories as follow:

\begin{tabular}{|l|l|}
\hline Percentages & $\begin{array}{l}\text { Practice } \\
\text { categories }\end{array}$ \\
\hline$\geq 80 \%$ & Satisfactory \\
\hline$<80 \%$ & Unsatisfactory \\
\hline $\begin{array}{l}\text { Chemotherapy } \\
\text { (Appendix III) }\end{array}$ & safety protocol \\
\hline
\end{tabular}

This guideline was designed to improve nurse's knowledge and practice during handling and administration of chemotherapy.

Tool validity and reliability:

It was established for test face and content validity of the suggested tool through panel of five experts who reviewed the tools for clarity, relevance, comprehensiveness, understanding, applicability and ease for implementation and according to their opinion minor modification were applied.

\section{Pilot study:}

A pilot study was carried out on sample of $10 \%$ of the nurses about (5 nurses) in units to evaluate the reliability and applicability of the tools and estimate the proper time required for answering the questionnaire. The tool was modified according to the results of the pilot study and expertise opinion and this number of the nurses was excluded from the sample. 
Field work:

The frame work of the study was carried out according to 4 phases as the following:

\section{A. Assessment phase}

After the official permission was taken from the dean of the faculty, head of Benha University Hospital and head of National Cancer Institute (NCI) at Cairo University, then the implementation phase was started. The researcher started by introducing herself to the nurses and giving them a brief idea about the aim of the study.

\section{B. Planning phase}

In this phase five sessions were be planned by the researcher for nurses to provide them with general knowledge about chemotherapy, and follow up safety measures during chemotherapy preparation and administration.

\section{Implementation phase}

The developed chemotherapy safety protocol was implemented for all nurses. It was conducted into 5 sessions each session took (30-45 minute) according to items that would be discussed. The nurses were divided into 9 small groups, each group consist of five nurses, during interview the researcher using questions, discussion, and other different teaching methods. During each session the researcher used brief, clear, simple words, and at end of each session a brief summary was given by the researcher.

\section{Evaluation phase}

Each nurse was interviewed individually after applying chemotherapy safety protocol for doing post-test through evaluating their knowledge and practice. Comparison between nurses pre-test and post-test finding were done to determine the effect of the chemotherapy safety protocol on nurse's knowledge and practice during chemotherapy preparation and administration.

\section{Ethical consideration:}

The aim of this study was explained to all nurses and they reassured that all information was confidential and it used only for their benefit and for research purpose. A verbal consent was taken from the study sample to participate in the study. The nurses have the right to withdraw at any time.

\section{Limitation of the study:}

The nurses were very busy so, the data collection was very difficult for the researcher to be completed in the same time. So the researcher divided nurses into groups and implemented chemotherapy safety protocol for each group separately. The small number of nursing staff included in this study which does not allow generalization of the result. Shortage of the equipment and supplies especially the disposable items (PPE). These were negatively affecting on nurses practices regarding protective measures.

\section{Results}

Table (1): This table mentioned that, above three quarter $(82.2 \%)$ of studied sample were females. In relation to age, above third $(42.2 \%)$ of studied sample were aged (from 19 to 29) years old. About marital status, above half (68.9\%) of studied sample were married. Regarding to level of education, it was found that near half $(44.4 \%)$ of studied sample had diplomat degree.

Figure (1): This figure illustrated that largest proportion $(84.4 \%)$ of studied sample having health problem, on the other hand less than third (15.6\%) of studied sample not having health problem due to chemotherapy handling.

Figure (2): This figure proved that there was a significant difference into nurse's knowledge about chemotherapy between pre, and post implementation of chemotherapy safety protocol.

Figure (3): This figure clarified that there was a significant difference into nurses practice pre, and post 
implementation of chemotherapy safety protocol.

Table (2): As observed from this table there was a significant relation between socio-demographic characteristic (agesocial status-education level-number of year as nurse) with nurses practice after implementing chemotherapy safety protocol where $p$ values were found to be $(p<0.05)$. While there was no a significant relation between socio-demographic characteristic (sex) with nurses practice after implementing chemotherapy safety protocol where $\mathrm{p}$ values were found to be $(\mathrm{p}>0.05)$.

Table (3): This table illustrated that there was no a significant relation between socio-demographic characteristic and nurses knowledge before and after implementing chemotherapy safety protocol where $\mathrm{p}$ values were found to be (p>0.05).

Table (4): As observed from this table there was a significant correlation between total nurses knowledge score and total practice score before implementing chemotherapy safety protocol where $\mathrm{p}$ values were found to be $(p<0.05)$. But there was high significant correlation between total nurses knowledge score and total practice score after implementing chemotherapy safety protocol where $\mathrm{p}$ values were found to be $(\mathrm{p}<0.001)$.

\begin{tabular}{|c|c|c|}
\hline \multirow{2}{*}{\begin{tabular}{|l|}
$\begin{array}{l}\text { Socio- } \\
\text { demographic } \\
\text { data }\end{array}$ \\
\end{tabular}} & \multicolumn{2}{|c|}{ Studied nurses } \\
\hline & $\mathrm{No}=45$ & $\%$ \\
\hline \multicolumn{3}{|l|}{ Sex } \\
\hline Female & 37 & 82.2 \\
\hline Male & 8 & 17.8 \\
\hline \multicolumn{3}{|l|}{ Age } \\
\hline $19-29$ & 19 & 42.2 \\
\hline $30-39$ & 18 & 40 \\
\hline More 40 & 8 & 17.8 \\
\hline \multicolumn{3}{|l|}{ Marital Status } \\
\hline Single & 9 & 20 \\
\hline Widow & 3 & 6.7 \\
\hline Married & 31 & 68.9 \\
\hline Divorced & 2 & 4.4 \\
\hline \multicolumn{3}{|l|}{ Education level } \\
\hline Nursing diplom & 20 & 44.4 \\
\hline Nursing technical & 17 & 37.8 \\
\hline Nursing bachelor & 8 & 17.8 \\
\hline \multicolumn{3}{|c|}{ Number of year as nurse } \\
\hline Less 3 year & 4 & 8.9 \\
\hline 3-5 year & 10 & 22.2 \\
\hline $5-10$ year & 10 & 22.2 \\
\hline More 10 year & 21 & 46.7 \\
\hline \multicolumn{3}{|c|}{ Number of year as oncology } \\
\hline Less 3 year & 18 & 40.0 \\
\hline 3-5 year & 13 & 28.9 \\
\hline 5-10 year & 7 & 15.6 \\
\hline More 10 year & 7 & 15.6 \\
\hline \multicolumn{3}{|l|}{ Work place } \\
\hline Out patient & 7 & 15.6 \\
\hline $\begin{array}{l}\text { Internal } \\
\text { department }\end{array}$ & 38 & 84.4 \\
\hline
\end{tabular}

Figure (1): Distribution of studied nurses regarding their health problem.

Figure (2): Distribution of studied nurses regarding total knowledge score pre, and post implementation of chemotherapy safety protocol.

Figure (3): Distribution of studied nurses regarding total practices score pre, 
and post implementation of chemotherapy safety protocol $(n=45)$.

Table (2): Relation between socio-demographic characteristics and total practices score pre and post implementation of chemotherapy guidelines $(n=45)$.

\begin{tabular}{|c|c|c|c|c|c|c|c|c|c|c|}
\hline & \multicolumn{4}{|c|}{ Pre } & \multicolumn{4}{|c|}{ Post } & \multirow{3}{*}{$\begin{array}{l}\mathbf{x 2 a} \\
\text { pre }\end{array}$} & \multirow{3}{*}{$\begin{array}{l}\mathbf{x 2} \mathbf{b} \\
\text { Post }\end{array}$} \\
\hline & \multicolumn{2}{|c|}{ Adequate } & \multicolumn{2}{|c|}{ Inadequate } & \multicolumn{2}{|c|}{ Adequate } & \multicolumn{2}{|c|}{ Inadequate } & & \\
\hline & No & $\%$ & No & $\%$ & No & $\%$ & no & $\%$ & & \\
\hline \multicolumn{11}{|l|}{ Sex } \\
\hline Female & 21 & 84.0 & 16 & 80.0 & 33 & 80.5 & 4 & 100.0 & $\begin{array}{c}0.94- \\
p>0.05\end{array}$ & $\begin{array}{c}0.12- \\
p>0.05\end{array}$ \\
\hline Male & 4 & 16.0 & 4 & 20.0 & 8 & 19.5 & 0 & 0.0 & & \\
\hline \multicolumn{11}{|l|}{ Age } \\
\hline $19-29$ & 7 & 28.0 & 12 & 60.0 & 17 & 41.5 & 2 & 50.0 & $\begin{array}{c}0.95- \\
p>0.05\end{array}$ & $\begin{array}{c}6.22- \\
p<0.05\end{array}$ \\
\hline $30-39$ & 11 & 44.0 & 7 & 35.0 & 16 & 39.0 & 2 & 50.0 & & \\
\hline More 40 & 7 & 28.0 & 1 & 5.0 & 8 & 19.5 & 0 & 0.0 & & \\
\hline \multicolumn{11}{|l|}{ Social Status } \\
\hline Single & 1 & 4.0 & 8 & 40.0 & 7 & 17.1 & 2 & 50.0 & $\begin{array}{c}2.69- \\
p>0.05\end{array}$ & $\begin{array}{l}11.61- \\
p<0.05\end{array}$ \\
\hline Widow & 3 & 12.0 & 0 & 0.0 & 3 & 7.3 & 0 & 0.0 & & \\
\hline Married & 19 & 76.0 & 12 & 60.0 & 29 & 70.7 & 2 & 50.0 & & \\
\hline Divorced & 2 & 8.0 & 0 & 0.0 & 2 & 4.9 & 0 & 0.0 & & \\
\hline \multicolumn{11}{|l|}{ Education level } \\
\hline Nursing diplomat & 15 & 60.0 & 5 & 25.0 & 19 & 46.3 & 1 & 25.0 & $\begin{array}{c}0.67- \\
p>0.05\end{array}$ & $\begin{array}{l}13.13- \\
p<0.05\end{array}$ \\
\hline Nursing technical & 10 & 40.0 & 7 & 35.0 & 15 & 36.6 & 2 & 50.0 & & \\
\hline Nursing bachelor & 0 & 0.0 & 8 & 40.0 & 7 & 17.1 & 1 & 25.0 & & \\
\hline \multicolumn{11}{|c|}{ Number of year as nurse } \\
\hline Less 3 year & 0 & 0.0 & 4 & 20.0 & 3 & 7.3 & 1 & 25.0 & $\begin{array}{c}2.28- \\
p>0.05\end{array}$ & $\begin{array}{c}8.20- \\
p<0.05\end{array}$ \\
\hline 3-5 year & 6 & 24.0 & 4 & 20.0 & 10 & 24.4 & 0 & 0.0 & & \\
\hline $5-10$ year & 4 & 16.0 & 6 & 30.0 & 9 & 22.0 & 1 & 25.0 & & \\
\hline More 10 year & 15 & 60.0 & 6 & 30.0 & 19 & 46.3 & 2 & 50.0 & & \\
\hline
\end{tabular}


Samah Abd-Elhai Abd-Elghani Shetaia et.al.

Table (3): Relation between socio-demographic characteristics and total knowledge score pre and post implementation of chemotherapy guidelines $(n=45)$.

\begin{tabular}{|c|c|c|c|c|c|c|c|c|c|c|}
\hline & \multicolumn{4}{|c|}{ Pre } & \multicolumn{4}{|c|}{ Post } & \multirow{3}{*}{$\begin{array}{l}\mathbf{x}^{2}{ }_{a} \\
\text { pre }\end{array}$} & \multirow{3}{*}{$\begin{array}{l}\mathbf{x}^{2}{ }_{b} \\
\text { Post }\end{array}$} \\
\hline & \multicolumn{2}{|c|}{ Inadequate } & \multicolumn{2}{|c|}{ Adequate } & \multicolumn{2}{|c|}{ Inadequate } & \multicolumn{2}{|c|}{ Adequate } & & \\
\hline & no & $\%$ & No & $\%$ & no & $\%$ & no & $\%$ & & \\
\hline \multicolumn{11}{|l|}{ Sex } \\
\hline Female & 29 & 82.9 & 8 & 80.0 & 4 & 100.0 & 33 & 80.5 & $\begin{array}{c}0.04- \\
p>0.05\end{array}$ & $\begin{array}{c}0.94 \ldots p \\
>0.05\end{array}$ \\
\hline Male & 6 & 17.1 & 2 & 20.0 & 0 & 0.0 & 8 & 19.5 & & \\
\hline \multicolumn{11}{|l|}{ Age } \\
\hline $19-29$ & 14 & 40.0 & 5 & 50.0 & 2 & 50.0 & 17 & 41.5 & & \\
\hline $30-39$ & 14 & 40.0 & 4 & 40.0 & 2 & 50.0 & 16 & 39.0 & $\begin{array}{c}0.62- \\
p>0.05\end{array}$ & $\begin{array}{c}0.95 . . p \\
>0.05\end{array}$ \\
\hline More 40 & 7 & 20.0 & 1 & 10.0 & 0 & 0.0 & 8 & 19.5 & & \\
\hline \multicolumn{11}{|c|}{ Social Status } \\
\hline Single & 6 & 17.1 & 3 & 30.0 & 0 & 0.0 & 9 & 22.0 & $\begin{array}{c}1.57- \\
p>0.05\end{array}$ & $\begin{array}{l}1.98 . . p \\
>0.05\end{array}$ \\
\hline Widow & 2 & 5.7 & 1 & 10.0 & 0 & 0.0 & 3 & 7.3 & & \\
\hline Married & 25 & 71.4 & 6 & 60.0 & 4 & 100.0 & 27 & 65.9 & & \\
\hline Divorced & 2 & 5.7 & 0 & 0.0 & 0 & 0.0 & 2 & 4.9 & & \\
\hline \multicolumn{11}{|c|}{ Education level } \\
\hline $\begin{array}{l}\text { Nursing } \\
\text { diplomat }\end{array}$ & 17 & 48.6 & 3 & 30.0 & 2 & 50.0 & 18 & 43.9 & $\begin{array}{c}1.14- \\
p>0.05\end{array}$ & $\begin{array}{l}0.34 . . p \\
>0.05\end{array}$ \\
\hline $\begin{array}{l}\text { Nursing } \\
\text { technical }\end{array}$ & 12 & 34.3 & 5 & 50.0 & 1 & 25.0 & 16 & 39.0 & & \\
\hline $\begin{array}{l}\text { Nursing } \\
\text { bachelor }\end{array}$ & 6 & 17.1 & 2 & 20.0 & 1 & 25.0 & 7 & 17.1 & & \\
\hline \multicolumn{11}{|c|}{ Number of year as nurse } \\
\hline Less 3 year & 3 & 8.6 & 1 & 10.0 & 0 & 0.0 & 4 & 9.8 & $\begin{array}{c}4.15- \\
p>0.05\end{array}$ & $\begin{array}{c}0.43 . . p> \\
0.05\end{array}$ \\
\hline $3-5$ year & 7 & 20.0 & 3 & 30.0 & 1 & 25.0 & 9 & 22.0 & & \\
\hline 5-10 year & 6 & 17.1 & 4 & 40.0 & 1 & 25.0 & 9 & 22.0 & & \\
\hline $\begin{array}{l}\text { More } 10 \\
\text { year }\end{array}$ & 19 & 54.3 & 2 & 20.0 & 2 & 50.0 & 19 & 46.3 & & \\
\hline
\end{tabular}

Table (4): Correlation between total knowledge score and total practices score pre and post implementation of chemotherapy guidelines $(n=45)$.

\begin{tabular}{|c|c|c|c|c|}
\hline \multirow{3}{*}{ practices } & \multicolumn{4}{|c|}{ Knowledge } \\
\cline { 2 - 5 } & $\mathbf{2}$ & $\mathbf{p}$ & $\mathbf{2}$ & Post \\
\cline { 2 - 5 } & $\mathbf{R}$ & $\mathbf{p}$ & 0.41 & $<0.001$ \\
\hline
\end{tabular}




\section{Discussion}

Chemotherapy exposure can affect on the nervous, integumentary, and gastrointestinal systems. Both acute side effects as headache, dizziness, nausea, vomiting, irritation, itching and long term side effects as genetic abnormalities in the offspring's of are noticed in the nurses. So safety guidelines, such as recommendations for using gowns, gloves and other PPE when handling chemotherapy drugs, have been issued by organizations such as the National Institute for Occupational Safety and Health, but these guidelines are not mandatory (10).

Therefore; the present study aimed to examine the effect of chemotherapy safety protocol for oncology nurses on their protective measure practices through: assessment of nurse's performance level (knowledge and practice) regarding chemotherapy at medical department at Benha University Hospital and National Cancer Institute (NCI) at Cairo University, designing and implementing chemotherapy safety protocol for nurses, and evaluating the effect of chemotherapy safety protocol on nurses' performance level (knowledge and practice).

The results of the present study revealed that above three quarter of studied sample were females, as in the same line (11) who reported that the majority of studied samples were females, and this may be attributed to the fact that most nurses in our community were females.

Regarding to age, the present study revealed that above third of studied sample were aged from nineteen to twenty nine years old. In contrast (12) who reported

that nearly half of study sample were aged more than forty one years old.

Concerning marital status, the results of the current study showed that above half of studied sample were married; this is in harmony with (13) who reported that above three quarter of sample was married.

As regard educational level, the present study revealed that near half of studied sample had diplomat degree. In contrast (14) who mentioned that the majority of studied nurses had baccalaureate degree.

The finding of the current study showed that near half of studied sample had years of experience as nurse more than 10 years. As in the same line (15) who mentioned that the majority of studied nurses had years of experience as nurse more than 10 years.

About years of experience in chemotherapy unit, the result of current study reported that near half of studied sample had year of experience less than 3 year. In the same line (16) reported that nearly half of study sample had less than five years of experience in chemotherapy unit.

Regarding work place, above three quarter of studied sample worked at inpatient unit, this is in harmony with (13) who reported that the majority of sample worked at inpatient unit. In contrast (17) who summarized that above half of nurses worked in outpatient unit.

The present study showed that the total pre knowledge score of studied sample was statistically significantly improved after implementing chemotherapy safety 
protocol. This is in line with (18) who stated that significant differences were found between the mean knowledge scores of nurses who had participated in an educational program compared with groups who had no formal education about chemotherapy.

The finding of present study reported that there were changes into nurse's practices after immediate implementation of chemotherapy safety protocol. This results supported by (13) who reported that there was statistical improvement in total practice score after educating nurse chemotherapy guidelines.

In the present study, there was positive relation between socio-demographic characteristic (age-social status-education level-number of year as nurse) and nurse's practice after implementing chemotherapy safety protocol. In consistence with (19) who reported that there was a significant relation between nurse's performance and socio-demographic characteristic.

The finding of current study revealed that there was no a significant relation between socio-demographic characteristic and nurses knowledge before and after implementing chemotherapy safety protocol. In contrast (20) who commented that there was a significant relation between socio-demographic characteristic and nurse's knowledge.

Finally, regarding correlation between total nurse's knowledge and total practice, the present study showed that there was a significant correlation between total nurse's knowledge score and total practice score before implementing chemotherapy safety protocol. But there was high significant correlation between total nurse's knowledge score and total practice score after implementing chemotherapy safety protocol. In contrast (21) who found that there was difference between level of knowledge and total practice.

\section{Conclusion}

\section{Finding of the present study concluded} that:

1- Nurses attending chemotherapy guidelines sessions had a significant improvement into their knowledge and practice about chemotherapy.

2- The present study provides an evidence base that chemotherapy guidelines were effective in improving nurses' practice during handling with chemotherapy.

3-There was a significant relation between socio-demographic characteristic (age social status - education level - number of year as nurse) and nurses practice after implementing chemotherapy guidelines.

4-There was no a significant relation between socio-demographic characteristic (sex) and nurses practice after implementing chemotherapy guidelines.

5-There was no a significant relation between socio-demographic characteristic and nurses knowledge before and after implementing chemotherapy guidelines.

6-There was a significant correlation between total nurses knowledge score and total practice score before implementing chemotherapy guidelines. 
CHEMOTHERAPY SAFETY PROTOCOL FOR ONCOLOGY NURSES etc...

7-There was high significant correlation between total nurses knowledge score and total practice score after implementing chemotherapy guidelines.

\section{Recommendation}

Based on finding of the present study the following recommendations can be suggested:

A. For the nurse:

1- Chemotherapy guidelines for oncology nurses should be revised, updated, and available in oncology unit in both Arabic and English language.

2- Continuous evaluation of nurse's knowledge and practice is essential to identify their needs about protective measures during handling with chemotherapy.

3- In-service training program must be developed based on need assessment for nurses in relation to chemotherapy.

B. Further studies are needed to:

1- Application of chemotherapy guideline for large sample from different geographical areas, for generalization of results.

2- Assessment of nurse's barrier that hinder their compliance with personnel protective equipment.

\section{References}

1 -Timby, B., and Smith, N. (2014): Introductory medical surgical nursing, (11 $1^{\text {th }}$ Ed.), Lippincott William\& Philadelphia, pp.(235341).
2- Conner, T., and Diarmid, M. (2016):

Preventing occupational exposures to Antineoplastic drugs in health care settings. A Cancer Journal for Clinicians 2006. Vol. (56), No. (1), pp. (354-365).

3- Moony, k. (2009): Mosby's Medical Dictionary, 9th edition. Available from. $\quad$ www.medicaldictionary.thefreedictionary.com/cyto toxic+drug. Accessed on 15/8/2015 at 1:00 PM.

4- Fransman, W., Vermeulen, R., and Kromhout, H.(2005): Dermal exposure to cyclophosphamide in hospitals during preparation, nursing and cleaning activities. Int Arch Occup Environ Health 2005;78:403-

412. 2.

5- Gehan, K., and WillemsonMcBride,T.(2009): Safe Handling

of Cytotoxic Agents: A Team Approach, AORN Journal. November 2009, Vol. (90), No. (5), pp. (731-740).

6-Victoria, T. (2013): Handling cytotoxic drugs in the workplace, Chapter(1) section(1),pp.(23).Availablefrom:ww w.worksafe.vic.gov.au/ data/assets/ pdf_file/0010/12223/handling_cytoto xic.pdf.pd. Accessed on 15/8/2015 at 3:30 PM. 
Samah Abd-Elhai Abd-Elghani Shetaia et.al.

7-California Institute of Technology.

(2011): Guidelines for the Use of

Cytotoxic

and

ChemotherapeuticDrugs.Availablefro

m. https://www.safety.caltech.edu/do

cuments/33cytotoxic_drugs_guidelin

es.pdf. Accessed on 15/8/2015 at

1:30 PM.

8-Health and Safety Executive. (2013):

Safe handling of cytotoxic drugs in

the workplace. Available from:

www.hse.gov.uk/healthservices/safe-

use-cytotoxic-drugs.htm. Accessed

on $15 / 8 / 2015$ at $4: 30 \mathrm{PM}$.

9- Gambrell, j., and Moore, S. (2006):

Assessing Workplace Compliance

With Handling of Antineoplastic

Agents. Clinical Journal of

Oncolgoy Nursing. August 2006.

Vol. (10), No. (4), pp. (473-477).

10-Live Science Staff. (2011): Nurses

Exposed to Toxic Cancer Drugs,

Study Finds

http://www.livescience.com/15721-

nurses-exposed-toxic-cancer-

drugs.html. Accessed on

6/1/2017 at 00:59 AM.

11- Kyprianou, M., Kapsou, M., Raftopoulos, V., and Soteriades, E.

(2010): Knowledge, attitude and beliefs of Cypriot nurses on the handling of antineoplastic agent.
European journal of oncology

nursing Vol. (1), No. (1), pp. (278-

282).

12-Sunita, K., Kaur, S., and Patel, F. (2009): Cytotoxic drug spillages among nursing personnel working in the chemotherapy administration areas. Nursing and midwifery research journal Vol. (5), No. (2), pp. (116-123).

13-Hafez, D. (2015): Nurse Protective Measures during Chemotherapy Preparation and Administration of Mansoura Oncology Center. Master degree, (1st Ed.).

14-Chaudhary, R., and Karn, B. (2012): Chemotherapy knowledge and handling practice of nurses working in a medical university of Nepal. JCT Vol. (3), No. (1), pp. (110-114).

15-Mohsen, M., and Fareed, M. (2013): Chemotherapy safety protocol for oncology nurses. World academy of science, Engineering and Technology, International Journal of Medical, Health, Biomedical, Bioengineering and pharmaceutical Engineering Vol. (7), No. (9), PP. (215-223).

16-Khan, N., Khowaja, K., and Ali, T. (2012): Assessment of knowledge, skill and attitude of oncology nurse 
CHEMOTHERAPY SAFETY PROTOCOL FOR ONCOLOGY NURSES etc...

in chemotherapy administration in tertiary hospital Pakistan. Open journal of nursing Vol. (5), No. (2), pp. (97-103).

17-Polovich, M., and Clark, P. (2010): Nurses use of hazardous drug. Safe handling and precautions. Open journal of nursing Vol. (3), No. (16), pp. (6).

18-Turk, M., Davas, A., Ciceklioglu, M., Sacaclioglu,F., and Mercan, T. (2004): Knowledge, attitude and safe behavior of nurses handling cytotoxic anticancer drugs in Ege university hospital. Asian pacific journal of cancer prevention Vol. (5), No. (1), pp. (164-168).
19-Mohamed, S., and Weheida, S.

(2014): Effect of implementing educational program about pressure ulcer control on nurses' knowledge and safety of immobilized patient. Journal of nursing education and practice Vol. (5), No. (3), pp. (1221).

20-Hussien, M. (2012): The impact of health education intervention on nurses' knowledge and practice for preventing infection in operating rooms in zagazig university hospital. Mansoura University, Faculty of nursing. Doctoral degree.

21-Attia, F. (2001): Effect of teaching program on prevention of nosocomial infection in peritoneal dialysis unit in Zagazig University Hospital. Doctoral thesis. Faculty of nursing. Zagazig University. Egypt pp. (149151). 